so it frequently happens that I use the word, sleep, quite sure that such a patient will not sleep, yet, with the mind centered upon not going to sleep, other suggestions incidentally brought forward are usually quite readily effective.

Concentration of gaze five minutes, followed by twenty full, rapid inhalations and exhalations are usually sufficient for operations that can be quickly performed, such as an opening of an abscess or extracting a tooth, but the breathing must be continued without stopping until the operation is finished.

For patients suffering from digestive disturbances, insomnia, tinnitus aurium (when aggravated by nervousness) or any affection for which it may be desirable to prescribe home treatment, the method of lying with the eyes closed and breathing as before described is by all means the best. Respiratory effort is of itself a beneficial exercise, easily understood and readily adopted by reason of its simplicity.

I have treated hypnotism as a disordinated state quite different from natural sleep, in which the subject is not open to suggestion and would awaken if suggestion were attempted, for, though denied by some, this distinction is well supported by eminent authorities, and accords fully with my own observations.

The objectionable features to hypnotism, Christian science and many methods of psycho-physics are:

To say nothing of the dangers of hypnotism as regards crime and physical injury, which, notwithstanding its repeated denial by ardent advocates, is still supported by a great amount of evidence. There is beyond question the fact that repeated hypnotization causes a dangerous susceptibility. Bernheim, Binet and Feret, Luys, Faveau, DuConormeilles, Hart, Cocke and many others all admit this fact, though some claim the danger can be avoided by suggestion; nevertheless, Hart took several of Luys' patients that had been given the usual suggestion not to let others hypnotize them, and in the presence of several reliable witnesses, induced the hypnotic state without difficulty; but assuming for the nonce, every physician to be equal to the harmless management of these difficulties from the point of view of the therapeutist, the essential and vital difference between the treatment here recommended and the hypnotic suggestion is, the one tends to build up, foster and encourage the will force and judgment of the patient, teaches selfreliance,and increases mental power. Whereas, the other weakens and destroys, in a measure at least, the inherent will power, takes away self-reliance and the valuable notion of personality. What physician, with the patient reduced to a mere automaton, subject to every word, every gesture, every look of the hypnotizer, can tell the exact physical state; when the patient, told that he is better, repeats; "Yes, I am better to-day," or marks any improvement that may be suggested to him, notwithstanding the fact that the disease may at the very moment be on the increase, with all the symptoms masked by his mental state.

Who is prepared to become "his brother's keeper," to say, "my mind is all right; I see and know all things clearly; I will be responsible for other minds and my own also?" Surely no one who has studied deeply into psycho-logical mysteries.

The so-called healers of Christian science, while they have done wonders in developing the field of mental treatment, deal in just this manner. Perhaps I speak a little bitterly, but $I$ have in mind a friend of mine, who was buoyed up with the false hope and fancied improvement suggested by those charlatans, until a cancer had stolen its way so deeply into his vitals that at least a number of years of his life, that otherwise might have been spared him by correct early diagnosis and the knife, had been lost.

The one thing that retards progress is a tendency to deception, particularly in this connection. Records of psycho-physics abound with lists of cases in which the patients have been deceived in this or that manner, given bread pills and water instead of the expected remedies, etc., throughout the familiar tricks. Now, while this may be very interesting in the light of experiments, lying and deception make, to say the least, a very unstable foundation upon which to build a therapeutic structure.

I have tried to strip this subject so far as possible of odious associates, believing that if accepted at all by the medical profession and accorded the place I feel it ought to have among legitimate therapeutic measures, its advance must be in a strictly conservative manner, without mysticism, and viewed only in the light of natural mental science.

$$
\text { BIBLIOGRAPHY. }
$$

Binet and Feret: Arimal Magnetism

Dr. Bernheim ; Suggestive Therapeutics; translated by Christian $A$. Harter, M.D.

Cocke, J. R.: Hypnotism; How it is Done; Its Uses and Dangers. Newbold. William Romaine.

DuConormeilles: Hypnotism.

Moll, Albert: Hypnotism

Brown, George V. I.: High, Light Shadow and Middletone of Hypism.

Hotchkiss, Elizabeth: Metaphysical Magazine.

Post, C. W.: I Am Well: Natural Suggestion, or Sclentia Vitæ.

Luys, J.: The Brain aud its Functions.

Carpenter, William B.: Mental physiology.

Tuke, Dauiel Hack: Influence of the Mind upon the Body.

Hart, E.: Hypnotism, Mesmerism and the New Witcheraft.

Sully, James: The Humane Mind.

Ladd, George T.: Outlines of Physiological Psychology.

Newbold, William Romaine: Suggestibility, Aucomatism and Kindred Phenomena: Normal and Heightened Suggestibility; Hypnotic Ifonthly, December, 1895 , to A pril, 1896, inclusive.

\section{THE PRACTICAL USES OF SUGGESTIVE THERAPEUTICS.} Read in the Section on Materia Medica, Pharmacy and Therapeutics, at tion, at Atlunta. Ga., Nay $5 \cdot 8,1896$.

BY WILLIAM LEE HOWARD, M.D.

BALTIMORE, MD.

I conceive it to be your desire to have a plain statement of the uses and limitations of suggestion, and I shall confine myself to this conception. To those of you who desire a more comprehensive statement of the psychologic side of the subject I refer to my paper read last year before the Neurologic Section of this Association.' In this paper I shall avoid as much as possible the misnomer hypnotism, as we shall see later on that often curative effects of suggestion are produced without inducing hypnosis. To anyone familiar with modern pathology the limitations of the therapeutic uses of suggestion will be readily understood. To those familiar with the trend of modern psychology its application for harmful effects will be fully appreciated. In treating patients by suggestion it is necessary to remember one fundamental factor, ie., the subjective state of the patients. Without this latter condition you will seldom succeed in effecting your object. Without doubt the reputation and success of most physicians is due to suggestion, often unconsciously made. The great factor in the large number of cases reported by Bernheim is

Hypnotism, its Uses, Abuses and Medico-legal Relations. Jour. Am. IIed. Asso., Nov. 30, 1895. 
due to the explicit confidence in him by his patients. We all know what a difference it makes in our successful treatment of patients when they have unbounded confidence in us; how soon they will respond to our suggestion; where, with a stranger, or one in whom they have little faith, treatment has apparently but slight effect. The same medicine given the patients by the physician with whom they are en rapport will have a far greater effect than if given by a stranger, provided that the former makes some simple but forcible suggestions regarding the effect of such medicine. When we start at the fundamental facts of suggestion it all appears very simple. To illustrate the force of suggestion I will give you a simple example. Let A., B. and C. agree to meet D. at different times and places during the day. Let them be men in whom he has confidence. On his way down to his office D. meets A.; A. exclaims: "Look here, D., what's the matter with you? You look very ill." etc. This suggestion acts with sufficient force to cause D. to drop in to a public place and consult a mirror. He soon sees that his face is pale and begins to feel weak. He throws off the idea for a while, but it will return to him at intervals. He then meets B. whose suggestions are more forcibly made; and afterward the third party. By this time, D. is in reality psychically ill, goes to his home and sends for his physician, who will find a rapid pulse and a generally disturbed condition. This is a fact that I have often demonstrated. Now, suggestion can act reversely. Hypnotism in all its stages is now an undisputed fact. Suggestion is a justifiable method in certain cases. In those obstinate and disagreeable cases of hysteria in all its forms; in insomnia, drug habit, and immoral practices which so often disrupt once happy homes, we here have a therapeutic remedy; and any physician, who, after he has made a correct diagnosis and failed to cure after using all his other resources, refuses to use suggestion either with, or without the aid of hypnosis, is not giving his patient that care and attention that he has a right to expect.

Unfortunately, through the daily press the subject has been placed in such a light as to have caused its beneficial factors to have been forgotten, and the older practitioner, with little or no knowledge of modern physiologic psychology, has looked askance at the subject. About this branch of medicine there has been too much haste, inaccuracy, fallacious reasoning, confused or contradictory ideas by a large number of our profession. I will now give you the practical side of the subject, leaving speculation and theory strictly alone. If I appear dogmatic it is only because I quote the reports of the most eminent and reputable men of science; and have not gone beyond the deductions derived from experience. I shall give you only the digest of the subject as reported the last twelve months.

The practical uses of suggestion are numerous. In certain forms of functional disturbances cures can be effected. The pains that often accompany organic diseases can be abolished. While suggestion will have no effect on organic disturbances per se, the relief of the accompanying pain is of vast importance, as it gives comfort and rest to the patient. The sensation of pain takes place in the cerebral cortex; it is a mental condition, it implies consciousness and hence, by an alteration in our state of consciousness as is induced by suggestion, pain can be abolished. Several cases have been reported of the cure of organic diseases of the cord. It is only necessary to say that either the observers were mistaken in the diagnosis, or allowed their enthusiasm to warp their judgment. The internal capsule, the thalamus, the motor convolutions, the sensory tracts in the cord once destroyed are not to be restored by any form of interference. It would appear at first thought that any such self-evident fact mentioned here was superfluous; but from the large num. ber of letters I receive from the profession I judge that this matter is not always understood.

I find, however, that I can greatly relieve a patient suffering from organic disease. The removal of anxiety, the implantation of new ideas, the removal of the habit of introspection, are oftentimes the means of breaking those vicious circles so common in the pathologic states, and removing the unpleasant psychic accompaniments. In my experience, insomnia offers the practitioner his best field for the treatment by suggestion. We can here see how it acts as a curative agent in so many functional disturbances. I generally see the patient at my office several times before attempting to produce hypnosis. After I have gained the confidence of the patient, and am satisfied as to the functional cause of the insomnia, I begin to suggest sleep. The symptoms of sleep are readily called up, they are familiar and natural, and therefore, a patient without possessing very great confidence in the operator can, without much difficulty, be made to believe that sleep has come upon him. This much gained, the patient's confidence in your powers are secured, and the field is ready for you to plant such suggestions as the conditions call for. ${ }^{2}$

Having your patient go to bed at the usual hour, you continually but forcibly suggest sleep. If you have succeeded in your tentative efforts you will be surprised to see how readily the patient will respond to your suggestions. Then I suggest how long she shall sleep, and that she will awaken refreshed and hungry. Be sure you tell her to sleep until a certain hour, for a subject under your perfect control will not always awaken unless the operator tells her to do so. One of my earlier experiences will illustrate. I was called to treat Mrs. M. who had been suffering from insomnia for several months. She responded to suggestions readily, and soon was in a state of hypnosis. About 9 o'clock the next morning there was a furious ringing of my door bell, an excited woman rushed in and said I had killed Mrs. M. Her family and friends had been trying for two hours to arouse her. Going immediately to the house I found family, physician and neighbors with their suggestions all there. Every method known to layman and doctor had been tried, but it was impossible to arouse Mrs. M. Going up to her I said firmly: "You must wake up now, Mrs. M.; wake up, wake up!" She opened her eyes and soon arose. It was her first good sleep for eight months, and the last time I ever forgot to suggest the duration of sleep to a patient.

The suggestive sleep by the Nancy method is harmless, and as far as my experience goes is a normal sleep produced by suggestion. The harm that comes from such a condition is due entirely to the purport of the suggestion made while in this receptive condition; evil suggestion can be given and will, to a certain extent, be accepted, as well as good." Hence, we can see the importance of regulating the practice so that it can only be used by reputable and skillful men. Next to insomnia suggestion is most useful in "z See Dr. Schofield's Lectures, Victorin Institute. London, 1896, "Relation of Nind and Body, or the Powers of Uuconscious Mind." 
hysteric seizures. In those troublesome hysterie ent status, the existing anesthetics. Local and comcontractures of the extremities, suggestion during plete anesthesia can be produced by suggestion, but it hypnosis seldom fails to give relief. Care must be is not available in an emergency case, unless the taken, however, not to attempt to correct contractures patient happens to be one in whom we have at prior of long standing, for as Charcot has said, when con- times produced complete anesthesia by this method. tracture has long existed, it becomes incurable. Hys- In minor operations when the time for operation can teric amaurosis is readily relieved by suggestion dur- be extended for a few days we can attempt to get our ing hypnosis. This is readily understood when we patient into that state of receptivity that will allow of realize that hysteric amaurosis is not a systematic producing a suggestive anesthesia. This can be selparalysis but a purely psychic amaurosis; a neutral- dom accomplished at the first attempt. When this ization of the object perceived by the imagination. anesthesia can be produced it is far superior to our Dr. Hugh Patrick reported to this Association at its present anesthetics; being devoid of any danger. Up last meeting at Baltimore a case of hysteric blindness to the present time we have had but one reported and pseudo-meningitis cured by suggestion. ${ }^{5}$ The authentic case of death from suggestion, and that long and tedious list of the different phases, types and death was due to the purport of the suggestion, so isomorphic forms of hysteria are all more or less forcibly made as to bring about the very result that amenable to treatment by suggestion. Cephalalgia, was suggested, i.e.. death. ${ }^{15}$ A case was reported last intellectual obnubliation, pseudo-hemi- and paraple- year from Paris as a death due to hypnotism. Prof. gias are conditions that are benefited by suggestion. Bernheim gives the following explanation. "A man

It is not always that the hysteria itself can be cured, but the symptoms can be removed. ${ }^{67}$ The treatment of dipsonnania by suggestion is now being quite extensively used. At the present time we are not in the position to make any dogmatic statement regarding its certainty as a remedial agent. I have had excellent results with cases that have tried about every other known treatment. The fact that you can abol. ish the nervous insomnia, eliminate the anorexia, and stop the tremors and other concomitants following an alcoholic debauch, is sufficient evidence to cause one to treat these cases by suggestion. With these functional disturbances controlled I use continued suggestion regarding the use of alcohol while the patient is in a state of hypnosis. The result has been very gratifying. Bushnell, Surg. U. S. A., says: "I have never failed to hypnotize a patient who sought treatment for alcoholism."

Dr. Am. De Jong reports very good results by this method of treatment during the last two years. ${ }^{9}$ Crothers ${ }^{10}$ advisesits employment whenever possible, and says: "Clinical experience furnishes many facts which seem to prove that in certain cases its value is very marked, also promising from more exact studies greater results." Dill ${ }^{11}$ gives a list of eight cases of dipsomnia treated successfully by suggestion. Green ${ }^{12}$ gives a case of a man addicted to the abuse of alcohol, bromids and chloral cured by four hypnotizations. What I have said concerning the alcohol habit refers also to the drug habits.

Sexual perversion as a disease has been but little studied in this country; but experience has proven to me that it is quite prevalent here. Suggestion is the only method of treatment so far known that has any effect on these cases. I refer to the acquired condition, not the congenital; the latter in my hands has never been benefited. Masturbation in both sexes is generally well controlled by suggestion. It would be a work of surplusage to enter into details upon this subject when we have such classic works as those of Kraft-Ebing, Schrenck-Notzing, Moll, Ellis and many others. $^{14}$ Hypnotism will never supplant, in its pres-

3, 4 Sre Tukey, Brit. Med. Jour. 1890, Vol. 12, 412-141. William Lee Howard, N. Y., Mred. Jour., March 9, 1895, 298-300.

Jomr. Am. Mod. Asso, Fel, 8, 1896.

Claus. A. et F. Jacobs. Un cas d'hystérie chez nue fillette de hui ans: gućrison par suggestion. Ann. Soc. de Mód. d' Anvers. JSyi.

i Kochs: Phénomiues hypnotiques chez une hystérique. Allgem. Zeitsch. f. Psychiatrie, t. l. iasc. $5,1894$.

Med. News, Phila, 1894, xiv, 337-343.

9 Inebriety and its Treatment by $\mathrm{Hy}$

10 Jour. Am. Med. Asso., Noy. 30, 1895. Quart. Jour., Inebriety, October, 1895. aged 37 years whom he had hypnotized to relieve the pain due to phlebitis of the leg, and whose death followed two hours afterward, was only an unfortunate coincident; as the postmortem showed death to be due to embolism of the pulmonary artery." I6 I have often operated in minor cases after putting the patient in a state of suggestive anesthesia. A large number of authentic cases have been reported. Wagner ${ }^{17}$ gives twenty-one cases of minor surgical operations done under suggestive anesthesia, and three obstetric cases. Major operations have also been done under the same conditions. It is very useful in obstetric cases. Here to be of any value you must have frequently hypnotized your patient, and have become certain that she will respond to your suggestions at any time. The advantages of suggestion in parturition are the removal of consciousness of pain, regulation of position of limbs, body and attitude, and increase of uterine contraction of voluntary muscles. In dentistry, for the extraction of teeth, it is a most satisfactory method of painlessly operating.

What percentage of persons can be controlled by suggestion? Authorities differ. The resuli will depend upon the individual operator, as in any other branch of medicine and surgery. A conservative estimate wonld be about 25 per cent. I succeed in about 30 per cent. What class of patients is most susceptible to suggestion? Phthisical patients; children between the ages of 5 and 15 years of age; those of a neurotic temperament; last and most difficult is the hypochondriac and the melancholic. The insane, imbecile and idiots seldom, if ever, respond to suggestion in any form. A certain class of normal intellect can not be controlled by suggestion. To use a hibernianism, they will insist on keeping awake to see how you will put them to sleep. What are the requirements to be successful in using suggestion? The tact, judgment, diagnostic ability and confidence in one's self and all that makes the successful physician. Suggestive therapeutics is no "royal road" to success. It involves the same application, severe attention and experience that is necessary in all branches of medicine and surgery. Until you have had some experience you will not have

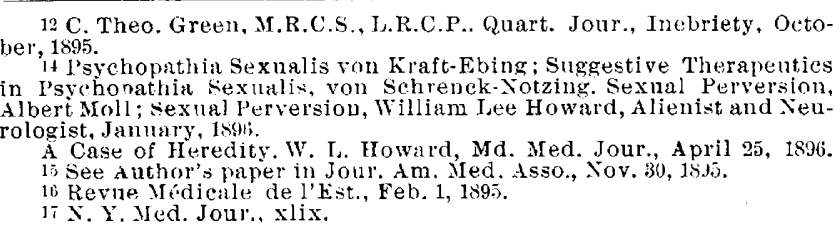
in Isychonathia Sexualis, von Schrenck-Fotzing. Sexual Perversion, Albert Moll; sexual Perversion, William Lee Howard, Alienist and Neurologist, January, 1s\$li.

A Case of Heredity. W. I. Howard, Md. Med. Jour., A pril 25, 1896. 15 See Author's paper in Jour. Am, iled. Asso., Sov. 30,1855

Feb. $1,189.5$

17 X.Y. Yed Jour. xlix. 
that full confidence that is necessary to impress your patient. There is no such thing as "will power," "animal magnetism," or any other so-called occult force employed. Get your patient, in a state of mental receptivity by having him look at some small bright object distant about six inches from the pupils and a little above them. When the eyelids begin to close, or a fibrillary motion commences, close them gently, and in a low but emphatic tone of voice suggest sleep. Once in this state the therapeutic suggestion should be made. In a large number of cases it is not necessary to produce complete hypnosis to get satisfactory therapeutic results. If the patient is only in a state of lucid lethargy he will often accept a suggestion with good results. A new idea of the explanation of the phenomena of hypnotism has just appeared..$^{18}$ This is no place for psychologic discussion or polemics, but as this idea has only been put before the profession the last few days I will call your attention to it. Dr. Henry Stark of Boston says: "Hypnotism is a pathologic process depending for its origin on contagium, probably specific in character, although unrecognizable by any of the five senses."

Suggestion as a therapeutic method of treatment is only an adjuvant. often a powerful one, to go hand in hand with other rational means of hygienic and medicinal treatment, and is not to be understood as by any means being a certain cure for all ills and complaints that man is heir to. It is not a catholicon, a philosopher's stone, as many enthusiasts would have us believe.

Psycho-physiology ${ }^{10}$ has placed suggestion on a sound scientific basis, and those who step from this basis and make claims that have no psychologic foundation, are those seized with the vertigo of the supernatural and condescend to serve as vouchers for the most absurd aberrations.

\section{THE ANTITOXIN OF TETANUS.}

Read in the Section on Nateria Medica, Pharmacy and Therapeutics at the Forty-seventh Annual Meeting of the American Medical

BY SAMUEL S. KNEASS, M.D. ASSOCIATE IN THE WILLIAM PEPPER CLINICAL LABORATORY, UNIVERSITY
OF PENNSYLVANIA.

Among the many principles on which are based our modern theories of the etiology and therapeutics of disease is that of the vaccinating or immunizing power of attenuated cultures of specific microörganisms. Although this principle is forecast by Jenner's discovery of the vaccine against variola, it is to the great Frenchman, Pasteur, that should be ascribed its first scientific development.

In 1880 this investigator showed that an attenuated culture of the microbe of chicken cholera, injected into animals, would produce a mild attack of the septicemia, and would leave them immune against a second attack. This was the first experimental fact to which numerous laboratory workers have been adding during the last fifteen years. Disease after disease has been added to the list, anthrax, hog cholera, malignant edema, hydrophobia, diphtheria, the infections due to the staphylococcus, the streptococcus and the pneumococcus, typhoid fever and tetanus.

It is not the purpose of this account to go into the

1 Psychic Infection: Remarks upon the Probability of a Mental Contagium, N. Y. Med. Record, April $18,1890^{\circ}$

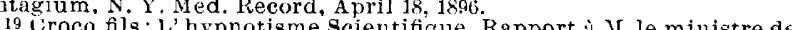
l'Interieur, a de l'instruction P'ublígue. Introduction de M. le Prof. Pitres, 1 1s96. history of the subject or the various theories of immunity except so far as they bear on the subject in hand, the antitoxin of tetanus and its use in the treat. ment of tetanus in the human being.

The bacillus of tetanus, first discovered by Nicolaier in 1884 in tetanic animals, and afterward by Rosenbach in 1885 , in the local lesion in man, was finally isolated and studied by the Japanese, Kitasato. Since then, these results have been approved by so many investigators, that we say definitely that it is proved that Nicolaier's bacillus is the specific cause of tetanus in all its clinical forms, traumatic, idiopathic, rheumatic, puerperal and of the new-born. It is the type of the specific intoxication. The bacillus growing only at the initial lesion there elaborates its toxin. An important point to remember is the extreme toxicity of the products of secretion of this bacillus. A 1-1,000 c.c. is sufficient, when injected subcutaneously, to kill an adult guinea pig. Evaporated to dryness this is represented by $0.000,025(25-1,000,000)$ $\mathrm{gm}$. A mouse succumbs to a dose of one-hundredth this quantity, $25-100,000,000 \mathrm{gm}$.

Brieger had found and isolated a ptomaine from tissues of a fatal case of tetanus, which he named tetanin. This was obtained also from cultures of the bacillus by Kitasato and Weyl. This substance kills animals with the characteristic symptoms of tetanus. But this is not the substance to which is due the intense intoxication of tetanus, and Brieger himself obtained a toxalbumin of much greater toxicity. This toxalbumin, the chemic relations of which we do not know, is probably only an impure form of the specific toxin; a mixture of the precipitated albumins and the toxin.

Brieger and Cohn (1893) were able to make a step in advance in the separation of a purer toxin. They used an intensely virulent veal-bouillon culture of tetanus bacillus. This they supersaturated with ammonium sulphate, and removing the supernatant precipitate, dried it on porcelain in a vacuum. Of this, $1 \mathrm{gm}$. was obtained for 1,000 c.c. of bouillon; and $1-10,000,000 \mathrm{gm}$. was sufficient to kill a $15 \mathrm{gm}$. mouse. But it was still impure. It was dissolved in water and was treated with a small amount of ammonia and basic acetate of lead to precipitate the albumins; dialyzed from twelve to forty-eight hours in running water to get rid of the peptones, salts, etc., and evaporated in vacuo at a temperature of 20 to 22 degrees C. This gave slightly yellow, transparent scales, odorless, with aromatic taste and soluble in water. It gave no reaction to Millon's fluid, nor responded to the xanthoproteic or biuret test. A slight violet color resulted with cupric sulphate and sodium hydrate; and no precipitation with the albumin precipitants, except ammonium sulphate. There was no phosphorus, and but a trace of sulphur. It is not, therefore, to be classed among the albumins. Of this substance but $1-20,000,000 \mathrm{gm}$. is sufficient to kill a mouse; or, assuming the action of the toxin to be similar in degree upon the human being, but about $\frac{1}{4} \mathrm{mg}$. would be fatal to a man weighing $70 \mathrm{~kg}$

Brieger and Boer have lately been able, by another method to procure a purer and more concentrated form of toxin, and also of antitoxin. Instead of alcohol or sulphate of ammonium they used salts of zinc, the sulphate or preferrably the chlorid. The filtered tetanus bouillon or the serum was diluted with five volumes of water and to this was added two volumes of a 1 per cent. solution of the salt. After 